\title{
Modeling of economic uncertainty
}

\section{Schjær-Jacobsen, Hans}

Published in:

Fuzzy Economic Review

Publication date:

2004

Document Version

Publisher's PDF, also known as Version of record

Link back to DTU Orbit

Citation (APA):

Schjær-Jacobsen, H. (2004). Modeling of economic uncertainty. Fuzzy Economic Review, 9(2), 49-73.

\section{General rights}

Copyright and moral rights for the publications made accessible in the public portal are retained by the authors and/or other copyright owners and it is a condition of accessing publications that users recognise and abide by the legal requirements associated with these rights.

- Users may download and print one copy of any publication from the public portal for the purpose of private study or research.

- You may not further distribute the material or use it for any profit-making activity or commercial gain

- You may freely distribute the URL identifying the publication in the public portal

If you believe that this document breaches copyright please contact us providing details, and we will remove access to the work immediately and investigate your claim. 


\section{FUZZY ECONOMIC REVIEW}

Volume IX, Number 2

November 2004

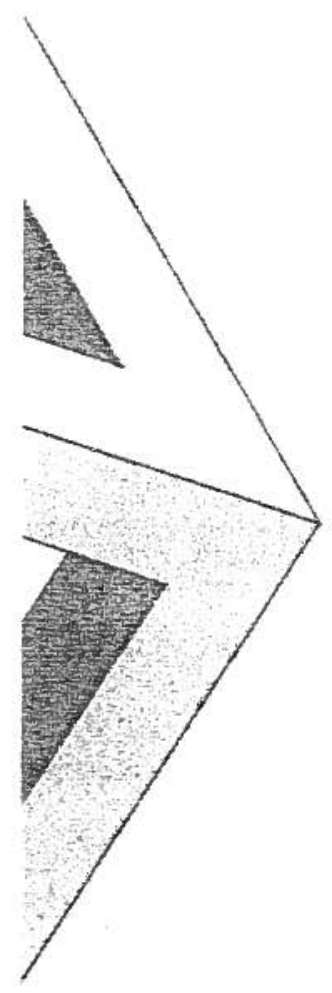

Modeling of economic uncertainty

Hans SCHJAER-JACOBSEN

Danfoss Management Institute

Danfoss AVS

DK-6430 Nordborg, Denmark

hsj@danfoss.com

THE REVIEW OF THE INTERNATIONAL ASSOCIATION FOR FUZZY-SET MANAGEMENT AND ECONOMY 


\title{
MODELING OF ECONOMIC UNCERTAINTY
}

\author{
Hans Schjær-Jacobsen
}

\begin{abstract}
Representation and modeling of economic uncertainty is addressed by different modeling methods, namely stochastic variables and probabilities (including Monte Cario simulation), interval analysis, and fuzzy numbers, in particular triple and quadruple esti-
\end{abstract}

mates. Focusing on discounted cash flow analysis numerical results are presented, comparisons are made between alternative modeling methods, and characteristics of the methods are discussed.

Keywords: economic uncertainty, modeling, stochastic, probability, Monte Carto, interval, fuzzy number, triple and quadruple estimate.

\section{INTRODUCTION}

This paper deals with an intricate issue in economic theory, however, from a practical point of view. The larger problem area under consideration is that of choice under risk and uncertainty and the practical perspective is that of modeling of economic uncertainty in practical decision situations.

Central to the modeling of economic uncertainty is the way in which uncertainty is actually represented numerically as a meaningful reflection of the character of uncertainty present. Further, the way of actually processing the uncertain input variables so that additional uncertainty is not introduced and finally the interpretation and communication of the model output variables as a basis for rational decision making is important.

The notion of risk and uncertainty being relevant for economic analysis was suggested by Knight (1921) and the concepts were incorporated into economic theory by von Neumann and Morgenstern (1944) who developed a rational foundation and rules for decision making according to expected utility, see also Hertz (1964). As far as risk and uncertainty is concerned Kyläheiko (1995) made an extensive study focusing on economic theory and methodology.

The distinction made by Knight (1921) between risk (the agent can assign mathematical probabilities to the randomness of the decision situation) and uncertainty (the actor cannot assign probabilities) has later been disputed by economists arguing that they are really representing one and the same thing. This debate is long running and far from being resolved at present. In this paper 
we shall refer to uncertainty not in the Knightian way but rather in a more general sense that allows us to refer to uncertain economic variables by means of a variety of different representations.

The traditional approach to representation of uncertainty in economic theory is that of probabilities. An uncertain variable may be represented by a probability distribution reflecting either the objective nature of the variable or the subjective belief of the agent.

The most common objectivist position argues that the probability of a particular event in a particular trial is the relative frequency of occurrence of that event in an infinite sequence of similar trials. Obviously, the idea of infinite repetition is referring to an idealized laboratory experiment like rolling an ideal dice an infinite number of times. How then is one to comprehend the probability of one-of-akind-events, such as the probability of a quote leading to an order?

Consequently, there have been many objections to this view of probability arguing that randomness is not an objectively measurable phenomenon but rather a knowledge phenomenon. Thus probabilities is rather an epistemological and not an ontological issue. This epistemic or knowledge view of probability can be traced back to Bayes (1763) and Laplace (1795). More recently Ramsey (1926) asserted that probability is related to the knowledge possessed by a particular individual and thus probability represents personal belief rather than objective knowledge.

We shall not take this discussion further but merely state that the position taken in this paper is to regard probabilities to be a way of representing uncertain knowledge. Accordingly, the numerical value of a probability is interpreted as being proportional to the sum of money a rational individual would be willing to pay should a proposition he asserts prove false. The measure of uncertainty so defined can be shown to obey the axioms of probability theory.

Probability theory and statistics today represent a well established mathematical theory with clear axioms and has reached an advanced stage of development. Since criticism has been raised towards probability theory as being a too normative framework to take all the aspects of uncertain judgement into account, Dubois and Prade (1988), we will investigate alternative methods of modeling economic uncertainties like the interval representation and the fuzzy number representation.

The interval representation, Moore (1962), lends itself to a situation where the knowledge of an uncertain parameter is limited to knowing its minimum and maximum value whereas nothing else is known. Based upon a mathematical theory of interval analysis this approach has shown to be useful in keeping track of worst and best cases in economic analyses and thus contribute to improved decision processes. 
The concept of fuzzy set was introduced by Zadeh (1965) for the purpose of modeling the imprecision and ambiguity of ordinary language. It is based on the concept of possibility rather than probability and translates natural language expressions into the mathematical formalism of possibility measures. It is widely recognized that possibility is distinct from probability. As mentioned earlier probabilities can be interpreted as relative frequencies or, more generally, imprecise knowledge or belief whereas possibility relates to the degree of feasibility and ease of attainment. In this paper the meaning of possibility will be quite clear from the particular applications presented.

\section{MODELING BY STOCHASTIC NUMBERS AND PROBABILITIES}

A stochastic variable $X=\{\mu ; \sigma\}$ is characterized by its expected value $\mu$ and its variance $\operatorname{VAR}(X)=\sigma^{2}$, where $\sigma$ is the standard deviation. As an example $\{1.000$; $100\}$ denotes the uncertain volume of sales during the next budgetary period, meaning that the sales volume is expected to be 1.000 with a standard deviation of 100 . In Fig. 1 an overview of the probability distributions used in this paper is shown.

Let $X_{1}$ and $X_{2}$ be independent stochastic variables with expected values $E\left(X_{1}\right)=$ $\mu_{1}$ and $E\left(X_{2}\right)=\mu_{2}$ and variances $\operatorname{VAR}\left(X_{1}\right)=\sigma_{1}{ }^{2}$ and $\operatorname{VAR}\left(X_{2}\right)=\sigma_{2}{ }^{2}$. It may be shown that basic calculations may be carried out according to the formulas shown in Table 1, see Schjær-Jacobsen (2002) for further details.

In the general case of $Y$ being a function of $m$ independent stochastic variables

$$
Y=Y\left(X_{1}, X_{2}, \ldots, X_{m}\right)
$$

we can approximate $Y$ by means of a Taylor series (ignoring second and higher order terms)

$$
Y \cong Y\left(\mu_{1}, \ldots, \mu_{m}\right)+\partial Y / \partial X_{1} \cdot\left(X_{1}-\mu_{1}\right)+\partial Y / \partial X_{2} \cdot\left(X_{2}-\mu_{2}\right)+\ldots+\partial Y / \partial X_{m} \cdot\left(X_{m}-\mu_{m}\right)
$$

where $\partial Y / \partial X_{i}$ is the partial derivative of $Y$ with respect to $X_{j}$ calculated at $\left(\mu_{1}, \ldots, \mu_{m}\right)$.

The variance is thus approximated by

$$
\operatorname{VAR}(Y)=\sigma^{2} \cong\left(\partial Y / \partial X_{1}\right)^{2} \cdot \sigma_{1}{ }^{2}+\ldots+\left(\partial Y / \partial X_{m}\right)^{2} \cdot \sigma_{m}{ }^{2}
$$

whereas the expected value is

$$
E(Y)=\mu=Y\left(\mu_{1}, \ldots, \mu_{m}\right)
$$

Obviously, in order to evaluate the results of a particular model in terms of $\mu$ and $\sigma$ an explicit formula (1) must be constructed and partial derivatives with respect to all variables (2) must be calculated. The procedure is quite simple in it self and does not require specific knowledge of the probability distributions of the variables involved besides the expected value and standard deviations. 
However, in cases of complex models having many variables the derivation and calculation of the partial derivatives may become elaborate.

Monte Carlo simulation has become a standard technique in obtaining estimated solutions to complex uncertainty models. The basic procedure is to assume uncertain variables to be represented by specific probability distributions and perform a large number of model calculations based upon randomly generated values of the uncertain parameters. Finally, by means of standard statistical methods the characteristics of the output parameters are determined and presented. For comparisons of alternative modeling techniques this paper makes use of the commercially available program Crystal Ball 2000, see Crystal Ball, 1998-2001, for carrying out Monte Carlo simulations.

\section{MODELING BY INTERVALS}

Recently it has been suggested to use intervals in order to represent uncertainties in connection with worst- and best-case (WBC) evaluation of economic consequences of technological development, Schjær-Jacobsen $(1996,1997)$. The interval approach was originally developed in 1962 by Moore $(1962,1966)$ in order to be able to keep track of the lower and upper bounds to the exact result when carrying out numerical calculations on digital computers with a finite number of significant digits. Following Moore (1966) we define an interval number as an ordered pair $[a ; b]$ of real numbers with $a \leq b$. It may also be defined as an ordinary set of real numbers $x$ such that

$$
a \leq x \leq b, \quad \text { or }[a ; b]=\{x \mid a \leq x \leq b\}
$$

If the basic operations addition, subtraction, multiplication, and division is denoted by the symbol \# we can define operations on two intervals $l_{1}=\left[a_{1} ; b_{1}\right]$ and $\mathrm{I}_{2}=\left[\mathrm{a}_{2} ; \mathrm{b}_{2}\right]$ based on the set-theoretic formulation:

$$
I_{1} \# I_{2}=\left\{x \# y \mid a_{1} \leq x \leq b_{1}, a_{2} \leq y \leq b_{2}\right\}
$$

Instead of this set-theoretic definition we may give alternative definitions in terms of endpoints of the resulting intervals by the formulas quoted in Table 1 . It should be mentioned that whereas the rules for basic calculations with intervals are commutative and associative they are not distributive.

In the case where an interval function to be evaluated is a monotone function of the intervals over their entire range the calculation is trivial. The resulting interval end points may simply be calculated at the end points of the variables. In the case of the interval function not being monotonic it is a different situation.

A simple example is the calculation of the non-monotonic expression $Y=I \cdot(1-1)$ where $I$ is an interval, $I=[0 ; 1]$. Straight forward application of the above mentioned formulas gives the result $Y=[0 ; 1]$ which obviously is a too wide interval. According to the fundamental definition of basic operations on intervals 
based upon set-theory (6), Moore (1966), the narrowest possible resulting interval should be $Y=[0 ; 1 / 4]$. In this paper the terms "true" or "correct" is used to indicate the narrowest possible bounds that can be calculated for an uncertain number. By using iterative global optimization methods, see f.ex. Hansen (1992), correct results may be obtained to an accuracy specified by the user. This feature has been implemented in a recent add-in module for MS-Excel by the name of Interval Solver 2000, Hywönen and De Pascale $(1999,2000)$.

\section{MODELING BY FUZZY NUMBERS}

Since the introduction by Zadeh (1965) fuzzy sets and fuzzy numbers have found a wide range of applications within the areas of engineering, management, and finance. A fuzzy set is a class of objects with a continuum of grades of membership defined by a membership function ranging from zero to one. The fuzzy set concept provides a convenient way of keeping precisely track with imprecise, vague, and uncertain informative statements such as "the class of all large investments". "costs will be considerably reduced in the coming period", and "the turn over will be a little larger next year".

Following Zadeh (1965) a fuzzy set $A$ in $X$ where $X$ is a space of points (objects) with a generic element of $X$ denoted by $X$, i.e. $X=\{X\}$, is characterized by a membership function $f_{A}(x)$ which associates with each point in $X$ a real number in the interval $[0 ; 1]$. The value of the membership function $f_{A}(x)$ at $x$ represents the "grade of membership" of $x$ in A. Thus the closer the value of $f_{A}(x)$ to unity, the higher the grade of membership of $x$ in $A$. Note, that when $A$ is an ordinary set, i.e. non-fuzzy, the membership function can take only two values 0 and 1 .

In other words, a fuzzy set is a set of ordered pairs $\left(x, f_{A}(x)\right)$

$$
A=\left\{\left(x, f_{A}(x)\right) \mid x \in X\right\}
$$

It may also be useful to define the ordinary (non-fuzzy) set $A_{\alpha}$ as the $\alpha$-cut of $A$ :

$$
A_{\alpha}=\left\{x \in X \mid f_{A}(x) \geq \alpha, 0 \leq \alpha \leq 1\right\}
$$

In this paper we are mainly interested in the concept of fuzzy numbers as a means of representing uncertain or fuzzy information, Dubois and Prade (1978, 1979 ). In addition to the simplest fuzzy number, namely the interval (6), we also make use of two more fuzzy numbers:

The first one is the triangular fuzzy number, Chiu and Park (1994), that can be defined the following way using real numbers $a \leq c \leq b$ :

$$
\begin{aligned}
f(x) & =(x-a) /(c-a), & & a \leq x \leq c \\
& =(b-x) /(b-c), & & c \leq x \leq b \\
& =0, & & \text { otherwise }
\end{aligned}
$$


The second one is the trapezoidal fuzzy number, Wang and Liang (1995), that may be given the following definition, $a \leq c \leq d \leq b$ :

$$
\begin{aligned}
f(x) & =(x-a) /(c-a), & & a \leq x \leq c \\
& =1, & & c \leq x \leq d \\
& =(b-x) /(b-d), & & d \leq x \leq b \\
& =0, & & \text { otherwise }
\end{aligned}
$$

Full basic operations on triangular fuzzy numbers may be facilitated by introducing the left $L(\alpha)$ and right $R(\alpha)$ representation of a fuzzy number $F$, refer to the $\alpha$-cut (8):

$$
F=[L(\alpha) ; R(\alpha)]
$$

where

$$
L(\alpha)=a+(c-a) \alpha \text { and } R(\alpha)=b+(c-b) \alpha, \quad \alpha \in[0,1]
$$

Observe, that in (11) F is written as an interval with upper and lower bounds depending on $\alpha$. This means that addition, subtraction, multiplication, and division can be carried out by means of the interval formulas in Table 1 by all values of $\alpha$. In the general case membership functions of arbitrary complexity may result and make the practical calculations prohibitively complicated.

One way of overcoming this difficulty is to limit the calculations to a finite number of values of $\alpha$. As an example of this consider the triple estimate defined by $\alpha$ cuts corresponding to the values $\alpha=0$ and $\alpha=1$, refer to (8).

Based on the above and also as a generalization of Kaufmann and Gupta (1988) we may now define basic operations on triple estimate triangular fuzzy numbers $F_{1}=\left[a_{1} ; c_{1} ; b_{1}\right]$ and $F_{2}=\left[a_{2} ; c_{2} ; b_{2}\right]$ by the formulas found in Table 1.

Based on the trapezoidal fuzzy number $(10)$ and using $\alpha$-cuts corresponding to the values $\alpha=0$ and $\alpha=1$, refer to (8), we may in a similar way define a quadruple estimate fuzzy number $F=[a ; c ; d ; b]$. Likewise, we get formulas for basic calculations with two quadruple estimates $F_{1}=\left[a_{1} ; c_{1} ; d_{1} ; b_{1}\right]$ and $F_{2}=\left[a_{2} ; c_{2} ; d_{2} ; b_{2}\right]$, see Table 1 . Note, that the calculations may be carried out by applying interval basic operations twice, once to yield the "outer" minimum and maximum $a$ and $b$ (corresponding to to $\alpha=0$ ) and once to yield the "inner" minimum and maximum $\mathrm{c}$ and $\mathrm{d}$ (corresponding to $\alpha=1$ ).

In the general case when calculating uncertain functions with triple estimate fuzzy number arguments care must be taken in order to produce true lower and upper limits. As an example consider the non-monotonic expression $Y=F \cdot(1-F)$, where $F$ denotes a triple estimate, $F=[0 ; 0,5 ; 1]$. The true triple estimate value of this expression turns out to be $Y=[0 ; 0,25 ; 0,25]$, which is not obtained by 
straightforward calculations because the variable $F$ appears twice in the expression. The remedy may be to use Interval Solver 2000, Hyvönen and De Pascale $(1999,2000)$, to calculate true lower and upper bounds by application of global optimization. The same holds for calculating with quadruple estimate arguments. The true value of the expression $Y=F \cdot(1-F)$, where $F$ is a quadruple estimate $F=[0 ; 0,25 ; 0,75 ; 1]$, is $Y=[0 ; 0,1875 ; 0,25 ; 0,25]$.

\section{EXAMPLES OF APPLICATIONS}

\subsection{PRESENT VALUE OF AN ORDINARY ANNUITY WITH UNCERTAIN RATE OF INTEREST}

The first example considered is the problem of calculating the present value PVA of an ordinary annuity of $\$ 1$ over $n$ periods of time at the rate of interest $r$,

$$
\text { PVA }=\left(1-(1+r)^{-n}\right) / r
$$

If the interest rate $r$ is subject to uncertainty, the present value PVA will also be uncertain.

\section{Stochastic modeling}

In the case of $r$ being represented by a stochastic variable $r=\left\{\mu_{r}, \sigma_{r}\right\}$ we get the stochastic function

$$
\text { PVA }=\{\mu, \sigma\}
$$

where

$$
\mu=\left(1-\left(1+\mu_{r}\right)^{-n}\right) / \mu_{r}
$$

For the standard deviation $\sigma$ we get by use of (3)

$$
\sigma \cong \partial \operatorname{PVA} \partial r\left(\mu_{r}\right) \cdot \sigma_{r}
$$

where

$$
\text { JPVAV} \partial r\left(\mu_{r}\right)=\left(n \cdot r \cdot\left(1+\mu_{r}\right)^{-n-1}+\left(1+\mu_{r}\right)^{-n}-1\right) / \mu_{r}^{2}
$$

is the partial derivative of PVA with respect to $r$ calculated at $\mu_{r}$.

\section{Comparison of alternative modeling methods}

Numerical calculations have been made in order to verify and compare the alternative methods of modeling and the results are shown in Table 2 . Some comments are in order.

Just for the sake of easy reference the first row shows the ordinary or "crisp" value of the annuity at a $5 \%$ rate of interest. The second row shows the calculation based on stochastic modeling according to the formulas (14) and (15). The third row reports a Monte Carlo simulation with a normally distributed 
rate of interest $r$ with the same expected value and standard deviation as in the second row. Ideally, the entries should produce identical results, which is not exactly the case. As far as the expected value is concerned the result of the second row is the exact one whereas that of the third row is approximated. In the case of the standard deviations both results are approximations.

In order to make comparisons the fourth to seventh row use input values of the rate of interest corresponding to expected values and standard deviations being identical to those of the second and third row. As for the expected values and standard deviations produced by the Monte Carlo method it is seen that the results depend only marginally upon the particular probability distribution used and for practical purposes may be considered identical to the values reported in the second row.

Although based on different theoretical concepts Monte Carlo simulation and interval modeling may be compared on the basis of the minimum and maximum values produced by identical inputs. Thus the fourth and sixth row should be compared and it is seen that the results are practically identical. By comparing the fifth and seventh row the identity of results is less pronounced. Generally the Monte Carlo simulation tends to produce narrower ranges than the interval method, the latter producing the true worst and best case results. This is even more pronounced in the next example.

\subsection{DISCOUNTED CASH FLOW ANALYSIS}

The second example considered is the net present value NPV calculated over $n$ periods by the function

$$
N P V=a_{0}+a_{1} \cdot\left(1+r_{1}\right)^{-1}+a_{2} \cdot\left(1+r_{1}\right)^{-1} \cdot\left(1+r_{2}\right)^{-1}+\ldots+a_{n} \cdot\left(1+r_{1}\right)^{-1} \cdot\left(1+r_{2}\right)^{-1} \cdot \ldots \cdot\left(1+r_{n}\right)^{-1}
$$

where $r_{1}, r_{2}, \ldots, r_{n}$ are the discount rates of interest and the net cash flow in the $i$ 'th period is given by the expression

$$
a_{i}=X_{i 1} \cdot X_{i 2}+X_{i 3}+X_{i 4}+\ldots+X_{i m}, \quad i=0, \ldots, n
$$

In practice, investment decisions are often taken based upon the NPV being positive and in cases of uncertain input parameters it is important to know the resulting uncertainty of NPV in order to match with the risk preferences of the decision makers, Schjær-Jacobsen et al. (2000).

\section{Stochastic modeling}

Let the relevant uncertain parameters in (17) and (18) be represented by known independent stochastic variables

$$
X_{i j}=\left\{\mu_{i j}, \sigma_{i j}\right\} \text { and } r_{i}=\left\{\mu_{i}, \sigma_{i}\right\}, \quad i=0, \ldots, n \text { and } j=1, \ldots, m
$$


While the expected value $\mu$ of NPV is easily calculated by inserting the expected values of the stochastic variables in formulas (46) and (47), we get for the variance $\sigma^{2}$ of NPV by means of (3):

$$
\begin{aligned}
\sigma^{2} & \cong\left(\partial N P V / \partial X_{01}\right)^{2} \cdot \sigma_{01}{ }^{2}+\left(\partial N P V / \partial X_{02}\right)^{2} \cdot \sigma_{02}{ }^{2}+\ldots+\left(\partial N P V / \partial X_{0 m}\right)^{2} \cdot \sigma_{0 m}{ }^{2}+ \\
& +\left(\partial N P V / \partial X_{11}\right)^{2} \cdot \sigma_{11}{ }^{2}+\left(\partial N P V / \partial X_{12}\right)^{2} \cdot \sigma_{12}{ }^{2}+\ldots+\left(\partial N P V / \partial X_{1 m}\right)^{2} \cdot \sigma_{1 m}{ }^{2}+ \\
& +\left(\partial N P V / \partial X_{21}\right)^{2} \cdot \sigma_{21}{ }^{2}+\left(\partial N P V / \partial X_{22}\right)^{2} \cdot \sigma_{22}{ }^{2}+\ldots+\left(\partial N P V / \partial X_{2 m}\right)^{2} \cdot \sigma_{2 m}{ }^{2}+ \\
& +\ldots+ \\
& +\left(\partial N P V / \partial X_{n 1}\right)^{2} \cdot \sigma_{n 1}{ }^{2}+\left(\partial N P V / \partial X_{n 2}\right)^{2} \cdot \sigma_{n 2}{ }^{2}+\ldots+\left(\partial N P V / \partial X_{n m}\right)^{2} \cdot \sigma_{n m}{ }^{2}+ \\
& +\left(\partial N P V / \partial r_{1}\right)^{2} \cdot \sigma_{1}{ }^{2}+\left(\partial N P V / \partial r_{2}\right)^{2} \cdot \sigma_{2}{ }^{2}+\ldots+\left(\partial N P V / \partial r_{n}\right)^{2} \cdot \sigma_{n}{ }^{2}
\end{aligned}
$$

where $\partial N P V / \partial X_{i j}$ is the partial derivative of NPV with respect to $X_{i j}$ calculated at $\mu_{i j}$ and $\partial N P V i \partial r_{i}$ is the partial derivative of NPV with respect to $r_{i}$ calculated at $\mu_{\mathrm{i}}$.

For the partial derivatives with respect to the X's in (49) we get for the 0'th period

$$
\begin{aligned}
& \partial N P V / \partial X_{01}=X_{02} \\
& \partial N P V / \partial X_{02}=X_{0} \\
& \partial_{N P V I \partial X_{0 j}}=1, \quad j=3, \ldots, m
\end{aligned}
$$

For the first period we get

$$
\begin{aligned}
& \partial N P V / \partial X_{19}=X_{12} \cdot\left(1+r_{1}\right)^{-1} \\
& \partial N P V / \partial X_{12}=X_{11} \cdot\left(1+r_{1}\right)^{-1} \\
& \partial N P V / \partial X_{1 j}=\left(1+r_{1}\right)^{-1}, \quad j=3, \ldots, m
\end{aligned}
$$

Likewise, for the second period we get

$$
\begin{aligned}
& \text { 2NPV/aX }{ }_{21}=X_{22} \cdot\left(1+r_{1}\right)^{-1} \cdot\left(1+r_{2}\right)^{-1} \\
& \partial N P V / \partial X_{22}=X_{21} \cdot\left(1+r_{1}\right)^{-1} \cdot\left(1+r_{2}\right)^{-1} \\
& \partial_{N P V / \partial X_{2 j}}=\left(1+r_{1}\right)^{-1} \cdot\left(1+r_{2}\right)^{-1}, \quad j=3, \ldots, m
\end{aligned}
$$

Generally, for the i'th period the partial derivatives are 


$$
\begin{aligned}
& \partial N P V / \partial X_{i 1}=X_{i 2} \cdot\left(1+r_{1}\right)^{-1} \cdot\left(1+r_{2}\right)^{-1} \cdot \ldots \cdot\left(1+r_{i}\right)^{-1} \\
& \text { DNPVIJX } X_{i 2}=X_{i 1} \cdot\left(1+r_{1}\right)^{-1} \cdot\left(1+r_{2}\right)^{-1} \cdot \ldots \cdot\left(1+r_{i}\right)^{-1} \\
& \partial N P V / \partial X_{i j}=\left(1+r_{1}\right)^{-1} \cdot\left(1+r_{2}\right)^{-1} \cdot \ldots \cdot\left(1+r_{i}\right)^{-1}, \quad j=3, \ldots, m
\end{aligned}
$$

Finally, the partial derivatives with respect to the rate of interests are calculated.

$$
\begin{aligned}
& \text { DNPV/ar } r_{1}=-a_{1} \cdot\left(1+r_{1}\right)^{-2}-a_{2} \cdot\left(1+r_{1}\right)^{-2} \cdot\left(1+r_{2}\right)^{-1}-\ldots-a_{n} \cdot\left(1+r_{1}\right)^{-2} \cdot\left(1+r_{2}\right)^{-1} \cdot \ldots \cdot\left(1+r_{n}\right)^{-1} \\
& \partial N P V / \partial r_{2}= \\
& -a_{2} \cdot\left(1+r_{1}\right)^{-1} \cdot\left(1+r_{2}\right)^{-2}-\ldots-a_{n} \cdot\left(1+r_{1}\right)^{-1} \cdot\left(1+r_{2}\right)^{-2} \cdot \ldots \cdot\left(1+r_{n}\right)^{-1} \\
& \partial N P V / \partial r_{n}= \\
& -a_{n} \cdot\left(1+r_{1}\right)^{-1} \cdot\left(1+r_{2}\right)^{-1} \cdot \ldots \cdot\left(1+r_{n}\right)^{-2}
\end{aligned}
$$

\section{Comparison of alternative modeling methods}

Consider the case of a possible investment in developing, manufacturing, and selling of an industrial product over a period of 5 years modeled by the formulas (17) - (25). Prior to the investment decision being taken a discounted cash flow analysis must be carried out in order to analyze the consequences of the future cash flows being known only with uncertainty. The following numerical calculations are all concerned with the same case, however with alternative representations of the uncertain variables.

We start out by representing all the uncertain values by means of their minimum and maximum values and the results of this interval modeling are shown in Table 3a. The resulting net present value is $[-3.532 ; 3.514]$ which is probably not satisfying a decision maker to authorize this project from a financial point of view because of a substantial possibility of creating a negative net present value.

The next method to be considered is the modeling by stochastic variables and the input variables in Table $3 b$ have been generated from uniform probability distributions corresponding to the intervals in Table $3 a^{\prime}$. The resulting net present value is seen to have an expected value of -111 and a standard deviation of 470 . A risk averse decision maker would probably not go ahead with the project because of the negative expected net present value and the relatively low probability of a positive result.

In Table 3c the Monte Carlo simulation has been used with uniform probabilities as input variables identical to those of Table $3 \mathrm{~b}$ and the result for the net present

\footnotetext{
'By this we mean that all input variables in Table $3 b$ have been created from the input variables $[a ; b]$ in Table $3 a$ by transforming them into uniform probability distributions with $\mu=(a+b) / 2$ and $\sigma^{2}=(b-a)^{2} / 12$.
} 
value is seen to have an expected value of -111 and a standard deviation of 468 and thus to be practically identical to that of Table $3 \mathrm{~b}$ using stochastic variables.

The insights from the calculations reported in Tables 3a-c may be summarized. It is noted that Monte Carlo simulations and representations by stochastic variables generates identical numerical results, compare Table $3 \mathrm{~b}$ and $3 \mathrm{c}$. From a practitioner's point of view this fact might serve as a confirmation of the correct derivation and programming of formulas (17) - (25) and, indeed, a correct implementation of the Monte Carlo simulation. Theoretically, however, the linearization (20) of the original non-linear model (17) - (18) may lead one to expect slightly varying results.

The Tables 4a-c represent similar sequencies of calculations, however starting out in Table 4a with triple estimates created by introducing most possible values between the minimum and maximum values shown in Table 3a. Obviously, from Table $4 a$, the net present value is now $[-3.532: 1.317 ; 3.514]$ and thus the investment appears to be more attractive then it was previously (Table 3a) although it is still quite possible to end up with a negative net present value. Note, that taking only the conventional "crisp" net present value of 1.317 into account would leave the decision maker with no reservations toward to the profitability of the project.

Again the stochastic variables in Table $4 b^{2}$ and the Monte Carlo simulation in Table $4 \mathrm{c}$ yield quite identical results for the net present value. By comparing with Tables $3 b$ and $3 c$ it is seen that the investment may now be evaluated as a more favourable one because of a positive expected net present value. This is a consequence of favourably skewed input variables compared to Tables $3 \mathrm{~b}$ and $c$.

An interesting observation based on the calculations reported in Tables 4a-c follows. Although the input variables (triangular fuzzy numbers in Table $4 a$ and triangular probability distributions in Table $4 b$ and $c$ ) have been derived from identical basic data, i.e. triple estimates [a; $c ; b]$, the resulting net present values may lead to alternative rhetorical arguments. In the case of triangular fuzzy number representation the most possible net present value is 1.317 whereas the expected net present value in case of a representation by triangular probability distributions is $313^{3}$, a quite substantial difference. Does this difference make the project less attractive from a probability point of view than from a possibility point of view? Not necessarily, the two figures may not be directly compared! The point is that although the basic input data are identical the arithmetic operations in the probability case are different from the operations in the possibility case and thus generates different numerical values of the resulting

${ }^{2}$ All input variables in Table $4 b$ have been created from the input variables $[a ; c ; b]$ in Table $4 a$ by transforming them into triangular probability distributions with $\mu=(a+b+c) / 3$ and $\sigma^{2}=\left(a^{2}+b^{2}+c^{2}-a b-a c-b c\right) / 18$.

${ }^{3}$ Which, by the way, is also (approximately) equal to the most probable net present value, see later. 
net present values. In the case of probabilities one may say that the characteristic value of the net present value (i.e. the expected value) is determined solely by the expected values of the input distributions. In the case of possibilities the characteristic value of the net present value (i.e. the most possible value) is determined solely by the most possible value of the input distributions. In other words, the most probable values of the probabilistic input variables are not propagated through the calculations defined by stochastic arithmetic (see the formulas in Table 1).

We are now going to compare the range minimum and maximum values of the net present value generated by the Monte Carlo simulation with the true values generated by the interval model. Doing the Monte Carlo simulation reported in Table $3 \mathrm{c}$ a range minimum and maximum for NPV of $[-1.841 ; 1.663]$ was produced which is seen to be much smaller than the true value of $[-3.532,3.515]$ from Table $3 a$, even if all the input variables were uniform distributions. Likewise, the Monte Carlo simulation reported in Table 4c resulted in an NPV of $[-1.166 ; 1.305]$ compared to the (still) true value from Table $3 a$ of $[-3.532 ; 3.515]$. It should consequently be concluded that the minimum and maximum values generated by the Monte Carlo simulation are far from the true values generated by the interval modeling technique.

From the Monte Carlo simulations it has been established by using the curve fitting facility of Crystal Ball that the resulting net present value in both cases can be fitted very closely to normal distributions even if all of the input variables are uniform distributions in the first case and triangular distributions (many being skewed) in the second case. In general this is to be expected when dealing with models beyond a certain size, i.e. with a large numbers of variables. This phenomenon may be attributed to the central limit theorem. It implies that no matter the particular form of the probability distributions used as input variables in the model, the final result will be close to a normal distribution, at least for all practical applications.

Finally, a quadruple estimate model is calculated in Table 5 . The net present value of $[-3.532 ; 299 ; 2.184 ; 3.514]$ may be interpreted in the following way: The most possible value of the net present value is uncertain but known not to be smaller than 299 and not to be larger than 2.184. At the same time it is known that the net present value will not be smaller -3.532 (worst case) and not larger than 3.514 (best case).

\section{SUMMARY AND CONCLUSION}

In this paper alternative ways of modeling economic uncertainty have been investigated. Economic variables have been represented and handled computationally in the following ways:

- Ordinary numbers, also called "crisp" numbers, computed by a standard spreadsheet program MS-Excel. 
- Double estimates, like intervals [a; b] computed by Interval Solver 2000 as an add-in module for MS-Excel, and stochastic variables $\{\mu, \sigma\}$ computed by means of approximate formulas developed for the particular economic models considered.

- Triple estimates of the form [a; $c ; b]$, being simplifications of triangular fuzzy numbers, computed by ordinary calculations in combination with Interval Solver 2000.

- Quadruple estimates of the form [a; c; d; b], being simplifications of trapezoidal fuzzy numbers, computationally handled by two consecutive applications of interval Solver 2000.

- Specific probability distributions like the uniform, the triangular, and the normal distribution in connection with Monte Carlo simulations, computed by Crystal Ball 2000 as an add-in module for MS-Excel.

One might ask the question which one of the modeling techniques mentioned should be preferred. First of all, it should be remembered that we try to handle imperfect knowledge by representing it in terms of uncertain numbers. Consequently, that representation should be chosen that most closely reflects the kind of imperfect knowledge at hand. Or vice versa, that kind of knowledge should be retrieved that most closely enables us to make conclusions relevant to the decision situation at hand.

In the case of the interval modeling approach, clearly you only need to know the true minimum and maximum values of the input variables. By applying Interval Solver $\mathbf{2 0 0 0}$ you will then easily arrive at the true minimum and maximum values of the output variables. The worst and best case argument goes like this: Provided the input variables stay within their bounds the output variables also will. In case of the triple estimate modeling approach you might even benefit from the advantage of being able to identify the most possible outcome by tracing the most possible values of the input variables. Once an ordinary spread sheet model for "crisp" calculations is developed it may be automatically intervallized by Interval Solver 2000 . From a communicative point of view the triple estimate approach is easily understood as an extension of an ordinary "crisp" calculation by adding true worst and best cases.

Obviously, application of quadruple estimates requires quite a lot of data. The advantage might be that follow-up activities after the investment has been made can be logically based on two zones of control. The first (and less critical) zone is that of controlling the model input variables staying inside the inner interval corresponding to the output parameters attaining the most possible values. The second (and more critical) zone is that of the input parameters staying inside the outer interval (but outside the inner interval) corresponding to the output parameters not attaining the most possible values but rather worse or better values.

On the other hand, if the independent variables are known in terms of expected values and standard deviations only the stochastic approach might be useful. 
The complication is that for each particular model the formulas governing the resulting standard deviations have to be derived. However, once derived the application is straight forward. Specific knowledge about the precise shape of the probability distributions is not needed and will not be known for the dependent variables either, except for the fact that in case of more complex models (typically more than 15-20 variables, according to experience) the dependent variables will be close to normal distributions. Thus $1 \%$ or $5 \%$ fractiles may be used instead of worst- and best cases to indicate practical limits to probable outcomes. One of the drawbacks of the stochastic model still is the difficulty of communicating with people unfamiliar with probabilities and statistics.

Finally, in cases where full information on the probability distributions is available Monte Carlo simulation may be useful. Once an ordinary spread sheet model is developed it is easily extended to run simulations and Crystal Ball 2000 offers a lot of additional functionalities, like further statistical analyses and creation of reports. As mentioned earlier reliable information on worst and best cases is not reported by Crystal Ball 2000 , one may have to resort to using fractiles. Depending on the required accuracy of the simulations this method may have to recalculate a particular model several thousand times and thus be much slower in terms of computer time needed compared to the other methods. On the other hand, it handles a variety of detailed statistical information.

In this paper we have focused on the representation and calculation aspects in order to evaluate the modeling characteristics and qualities of competing approaches. Never the less, it should be born in mind that the crucial point in practical applications to decision making still is the ability of the decision maker to "know" something about the future states of the world subject to uncertainty and then, simultaneously, to be able to handle that uncertainty in adequate ways.

\section{REFERENCES}

BAYES, T. (1763). "An essay towards solving a problem in the doctrine of chances". Reprinted 1970 in Pearson and Kendall (editors) Studies in the History of Statistics and Probability.

CHIU, C.U.; PARK, C.S. (1994). "Fuzzy cash flow analysis using present worth criterion". The Engineering Economist, Vol. 39, No. 2, p. 113-138.

CRYSTAL BALL, 1998-2001. User Manual Crystal Ball 2000.2. Standard Edition, Version 5.2 Decisioneering inc., Denver, Colorado, USA.

DUBOIS, D.; PRADE, H. (1978). "Operations on fuzzy numbers". Intemational Joumal of System Science, Vol. 9, p. 613-626.

DuBOIS, D.; PRADE, H. (1979). "Fuzzy real algebra: Some results". Fuzzy Sets and Systems, Vol. 2. p. $327-348$.

DUBOIS, D.; PRADE, H. (1988). Possibility theory - An approach to computerized processing of uncertainty. Plenum Press, New York.

HANSEN, E. (1992). Global optimization using interval analysis. Marcel Dekker, New York, USA.

HERTZ, D.B. (1964). "Risk analysis in capital investment". Harvard Business Review, January/February 1964, p. 95-106. 
HWONEN, E.; DE PASCALE, S. (1999). "A new basis for spreadsheet computing: Interval Solver for Microsoft Excel". Proceedings of the $11^{\text {th }}$ Innovative Applications of Antificial intelligence (IAAI99), AAAI Press, Menlo Park, Califomia.

Hrvónen, E.; DE PASCALE, S. (2000). Interval Solver 2000 for Microsoft Excel. User's Guide, Version 4.0. Program Release 4.0.0.2. Delisoft Lid., Helsinki, Finland.

KAUFMANN, A.; GUPTA, M.M. (1988). Fuzzy mathematical models in engineering and management science. Elsevier Science Publishers B.V.

KNIGHT, F.H. (1921). Risk, uncertainty, and profit. Houghton Miffin، Boston.

KYLAHEIKO, K. (1995). Coping with technology: A study on economic methodology and strategic management of technology. Doctoral dissertation, Lappeenranta University of Technology, Finland.

LAPLACE, P.S. (1795). A Philosophical essay on Probabilities. 1951 translation, Dover, New York, USA.

MOORE, R.E. (1962). Interval arithmetic and automatic error analysis in digital computing. Ph.D. dissertation, Stanford University.

MOORE, R.E. (1966). Interval analysis. Prentice-Hall, Englewood Cliffs, New Jersey, USA

VON NEUMANN, J.; MORgENSTERN, O. (1944). Theory of Games and Economic Behavior. 1953 edition, Princeton University Press, Princeton, New Jersey, USA.

RAMSEY, F.P. (1926). "Truth and Probability" in: Braithwaite (editor) (1931), The Foundations of Mathematics and Other Logical Essays, Chapter 7. Routledge, London, UK.

SCHJAER-JACOBSEN, H. (1996). "A new method for evaluating worst-and best-case (WBC) economic consequences of technological development". Intemational Joumal of Production Economics, Vol. 46-47, p. 241-250.

SCHJER-JACOBSEN, H. (1997). "Handling economic risks and uncertainties of production technology investments". Proceedings of the $14^{\text {th }}$ Intemational Conference on Production Research, Osaka, Japan, August 4-8, 1997. Vol. 1, p. 346-349.

SCHJAER-JACOBSEN, H.; THUNEBY, J.; MADSEN, K. (2000). "Representation, calculation, and decision making under economic uncertainty". (In Danish). Lede/se og Ertvervsøkonomi, Vol. 64, No. 3 p. 133-148.

SCHJAER-JACOBSEN, H. (2002). Modeling of Economic Uncertainty, Internal Report, Danfoss Management Institute, Danfoss, Nordborg, Denmark.

WANG, M.-J.; LIANG, G.-S. (1995). "Benefit/cost analysis using fuzzy concept". The Engineering Economist, Vol. 40, No. 4, p. 359-376.

ZADEH, L.A. (1965). "Fuzzy sets". Information and Control, Vol. 8, p. 338-353. 


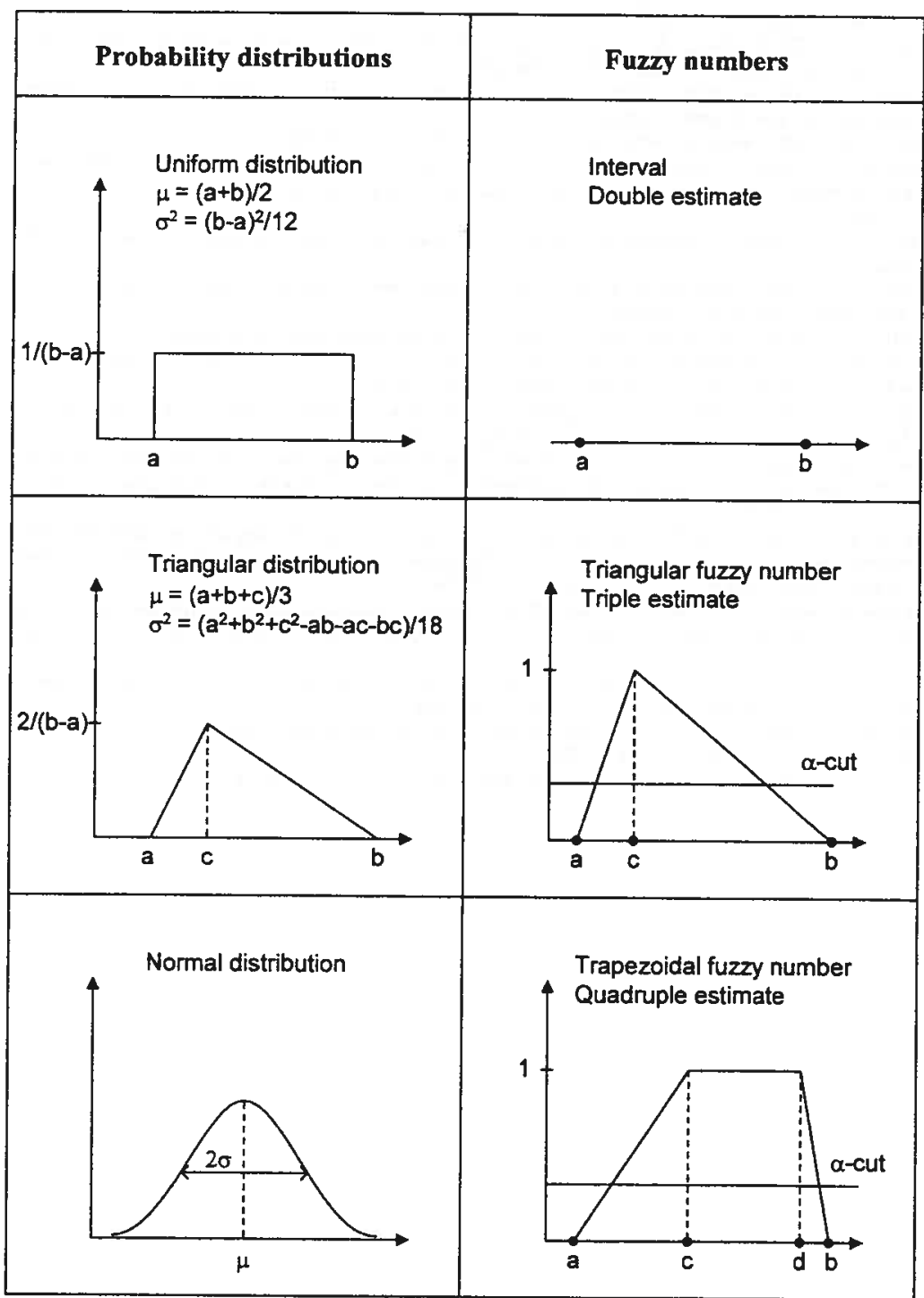

Figure 1. Probability distributions and fuzzy numbers used in this paper 


\begin{tabular}{|c|c|c|c|c|}
\hline 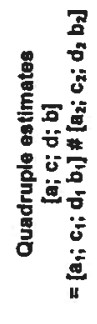 & 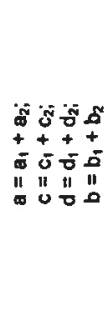 & 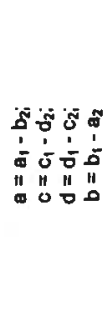 & 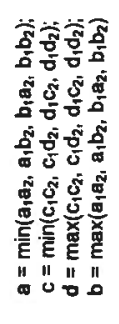 & 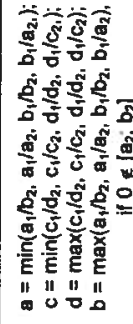 \\
\hline 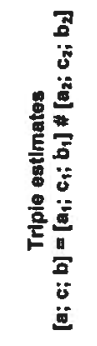 & 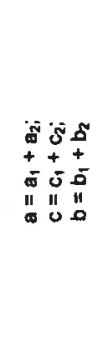 & 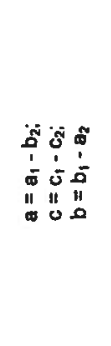 & 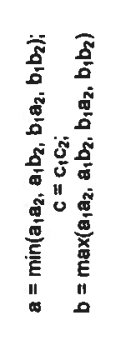 & 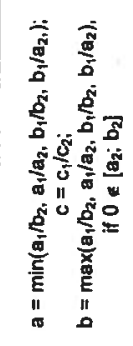 \\
\hline 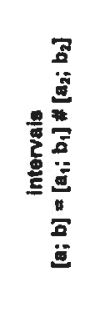 & 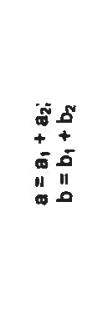 & 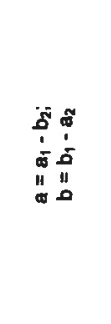 & 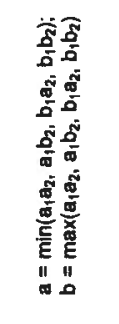 & 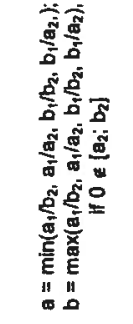 \\
\hline \multirow[t]{2}{*}{ 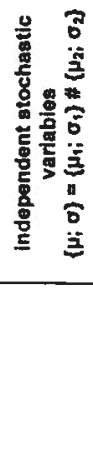 } & 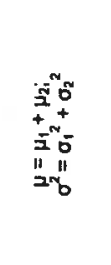 & 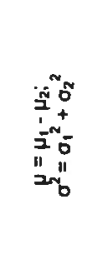 & 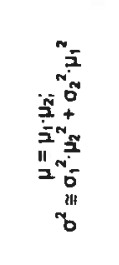 & 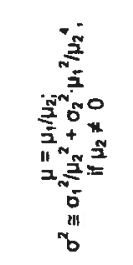 \\
\hline & 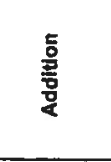 & 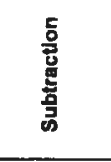 & 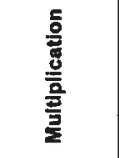 & 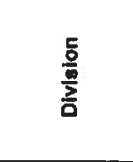 \\
\hline
\end{tabular}




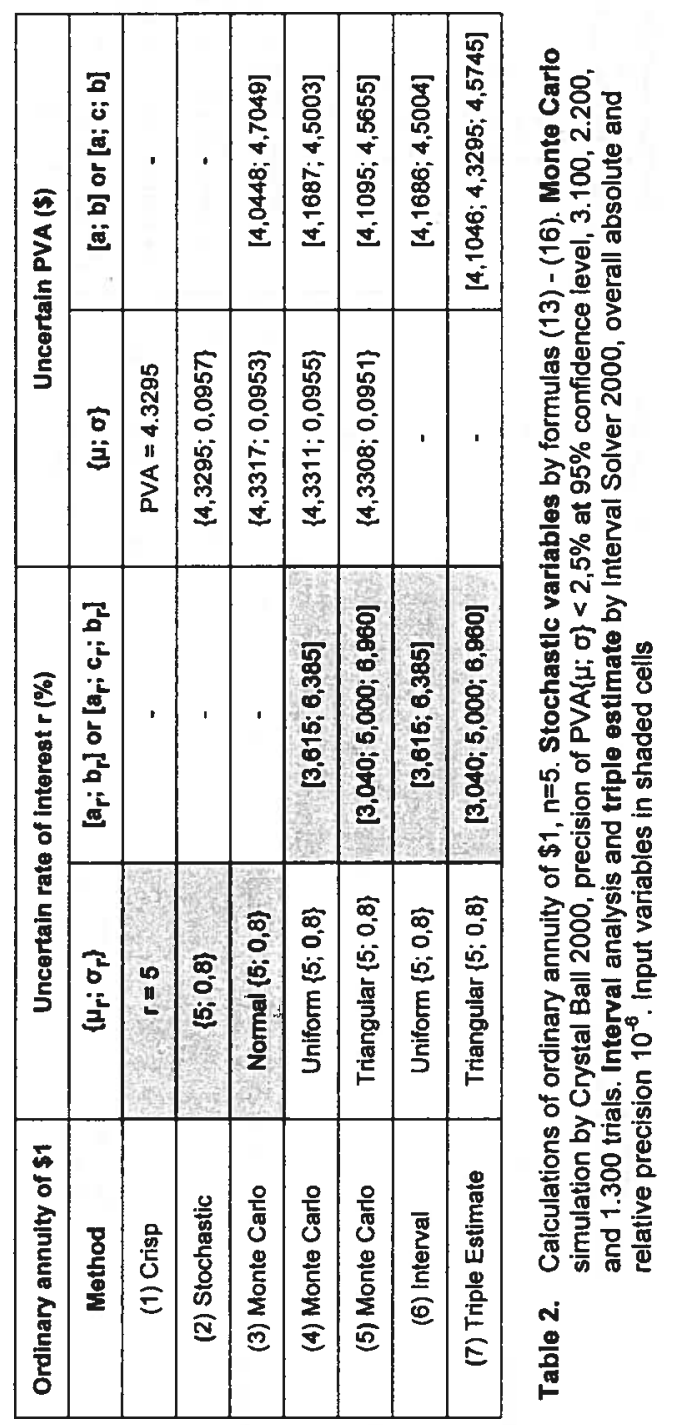




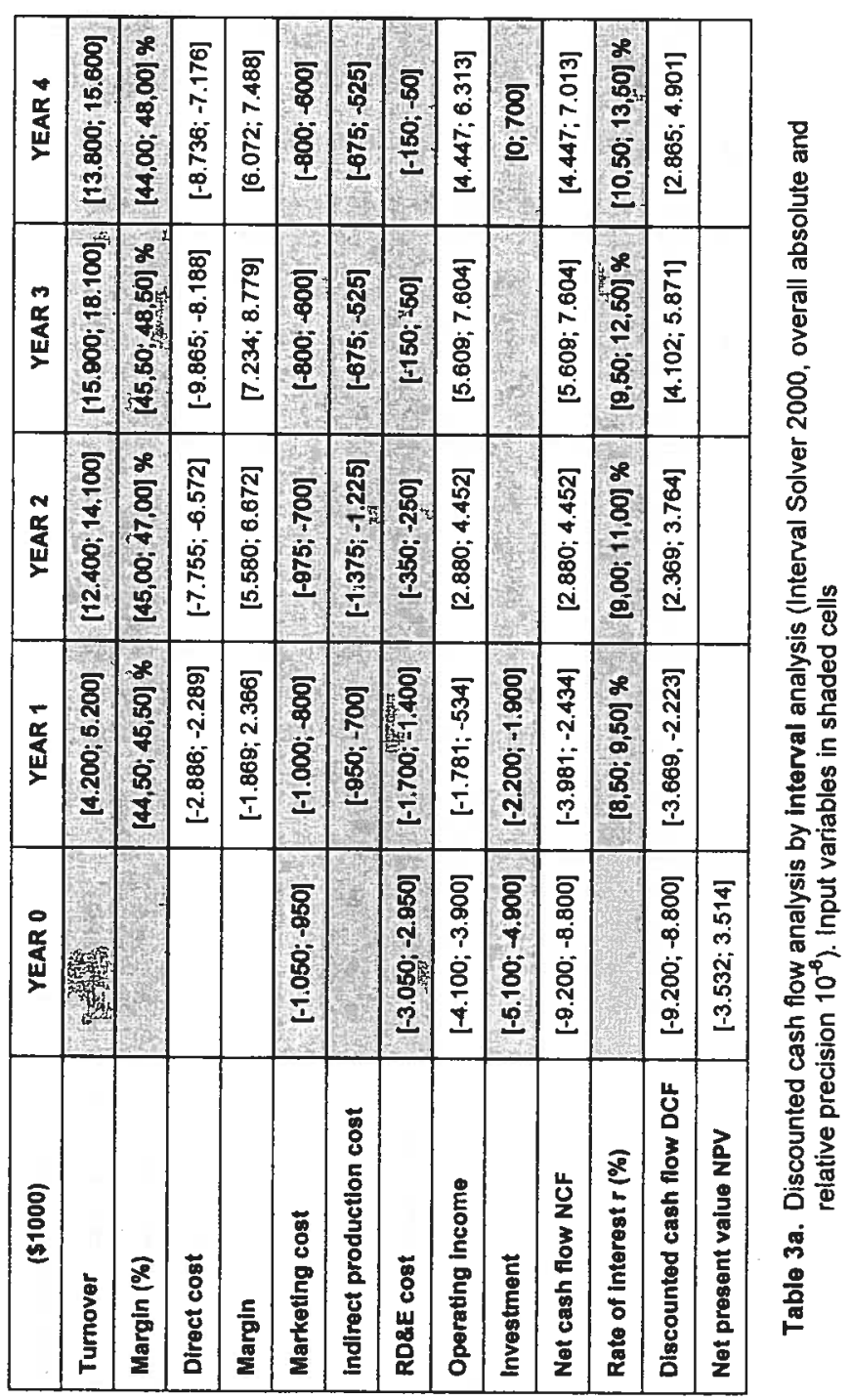




\begin{tabular}{|c|c|c|c|c|c|c|c|c|c|c|c|c|c|}
\hline$\underset{⿱ 亠 凶}{\vec{\psi}}$ & 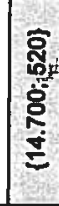 & $\frac{x}{5}$ & 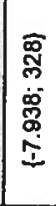 & 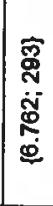 & 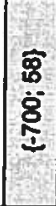 & $\begin{array}{l}\widehat{\alpha} \\
\bar{q} \\
\overline{8} \\
\overline{8}\end{array}$ & 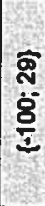 & 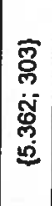 & 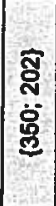 & 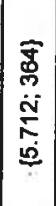 & 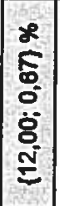 & 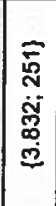 & \\
\hline 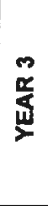 & 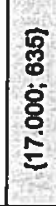 & 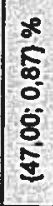 & 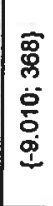 & 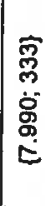 & 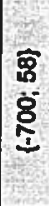 & $\begin{array}{l}\overline{3} \\
\dot{8} \\
\end{array}$ & 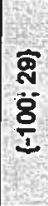 & 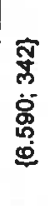 & 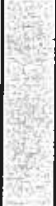 & 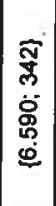 & 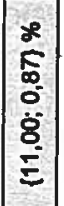 & 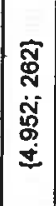 & \\
\hline$\underset{\tilde{z}}{\tilde{z}}$ & 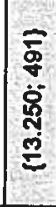 & 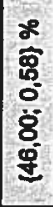 & 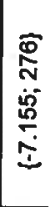 & 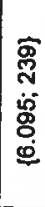 & 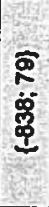 & 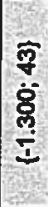 & $\begin{array}{l}\widehat{\Phi} \\
\overline{8} \\
\bar{q}\end{array}$ & 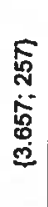 & & 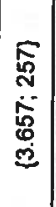 & $\mid \begin{array}{c}x \\
\overline{8} \\
0 \\
0 \\
8 \\
0 \\
0 \\
0\end{array}$ & 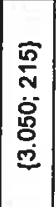 & \\
\hline$\underset{\underset{\nu}{\alpha}}{\bar{\alpha}}$ & 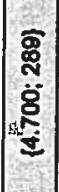 & 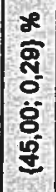 & 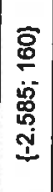 & & $\begin{array}{l}\bar{\Phi} \\
\overline{8} \\
\dot{\$} \\
\Phi\end{array}$ & 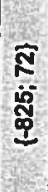 & 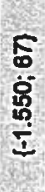 & 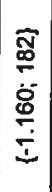 & 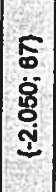 & 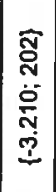 & 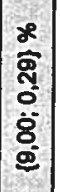 & 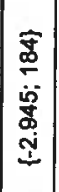 & \\
\hline 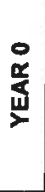 & & & & & 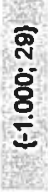 & & 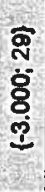 & $\begin{array}{l}\text { 宗 } \\
\dot{8} \\
\dot{I} \\
\end{array}$ & $\begin{array}{l}5 \\
0 \\
\dot{8} \\
8 \\
\dot{8}\end{array}$ & $\begin{array}{c}\hat{T} \\
\dot{0} \\
\vdots \\
\dot{0} \\
\dot{i}\end{array}$ & & $\begin{array}{c}\hat{\pi} \\
\dot{8} \\
8 \\
\dot{0} \\
1\end{array}$ & 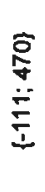 \\
\hline & 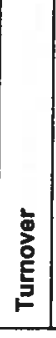 & $\begin{array}{l}\overline{\underline{\underline{z}}} \\
\overline{\overline{\bar{w}}} \\
\overline{\mathbf{m}}\end{array}$ & 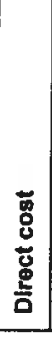 & $\begin{array}{l}\text { 들 } \\
\text { 홀 }\end{array}$ & 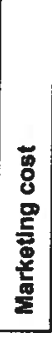 & 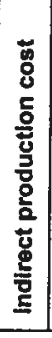 & 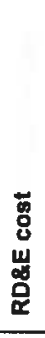 & 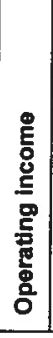 & 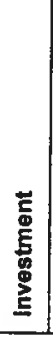 & 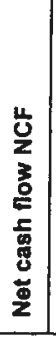 & 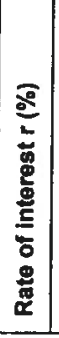 & 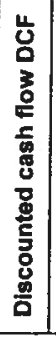 & 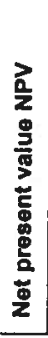 \\
\hline
\end{tabular}




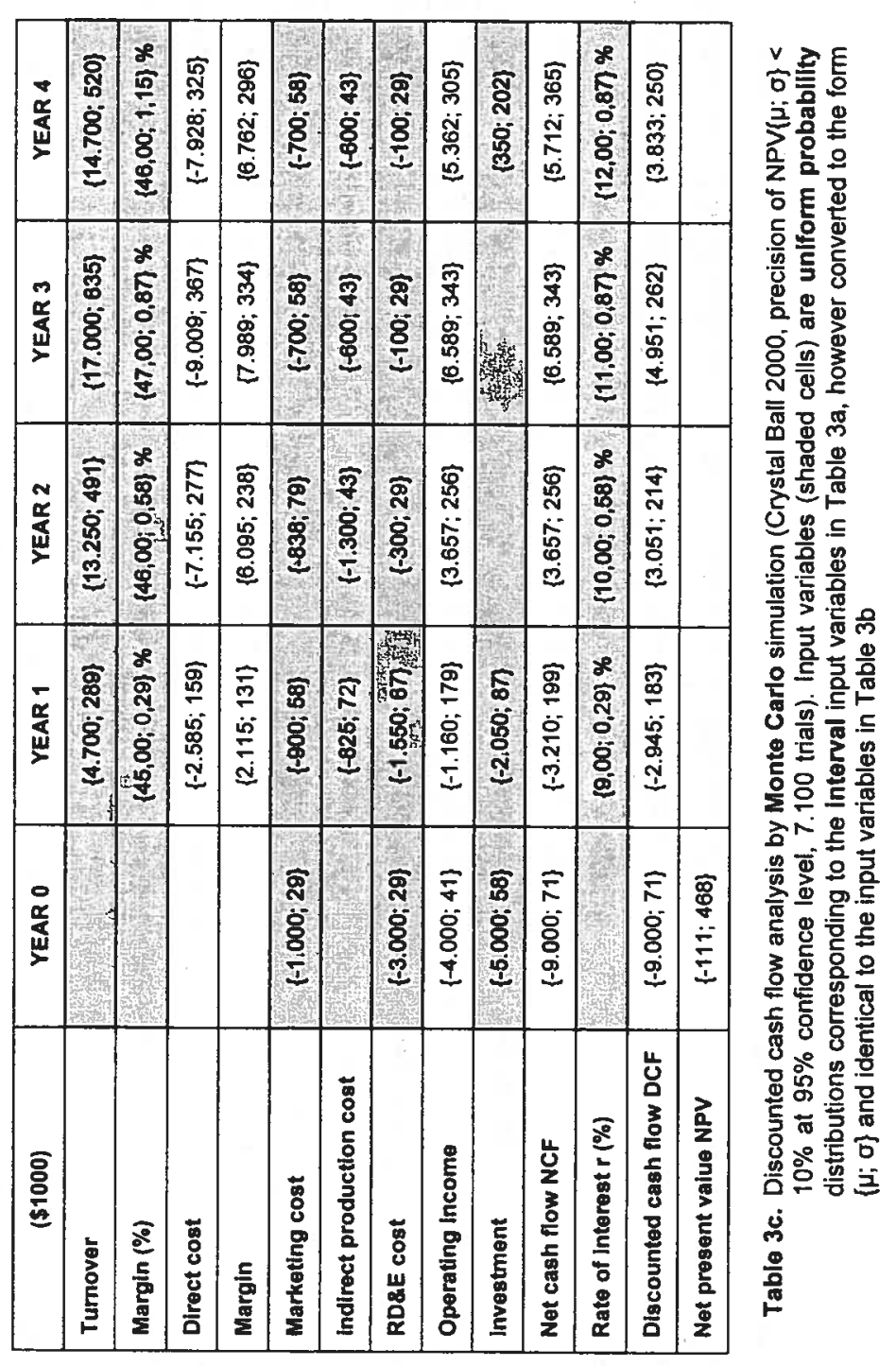




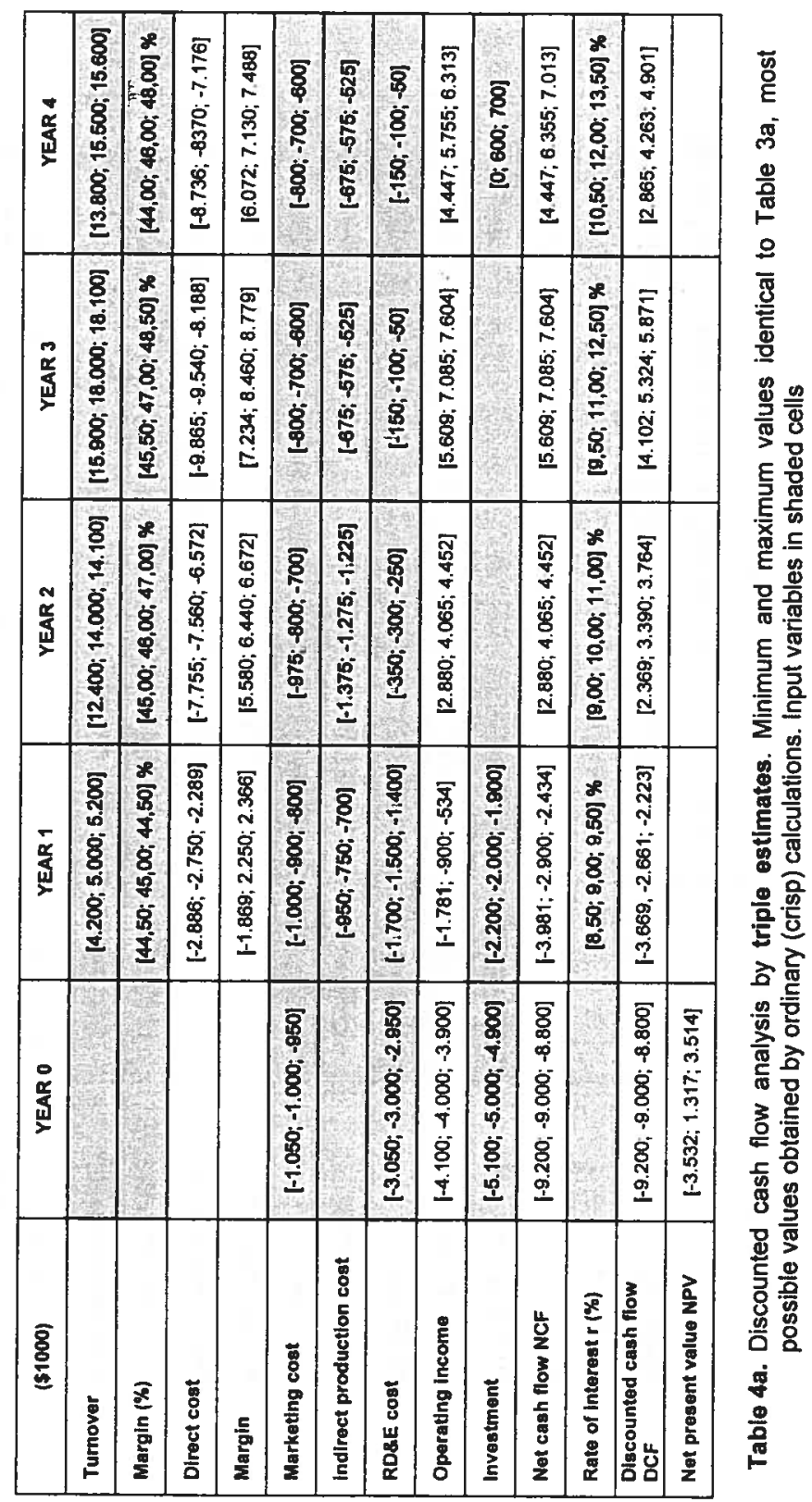




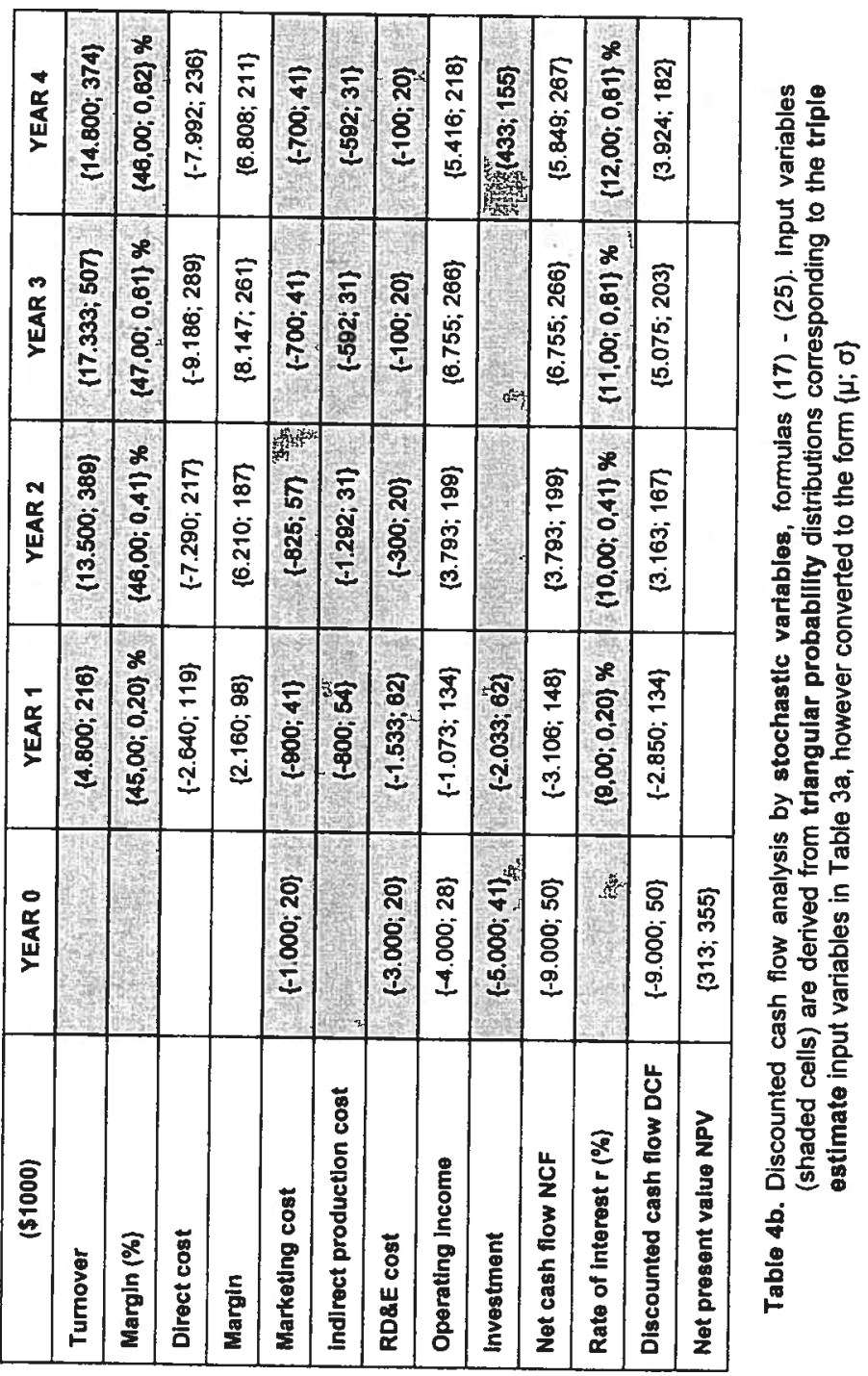




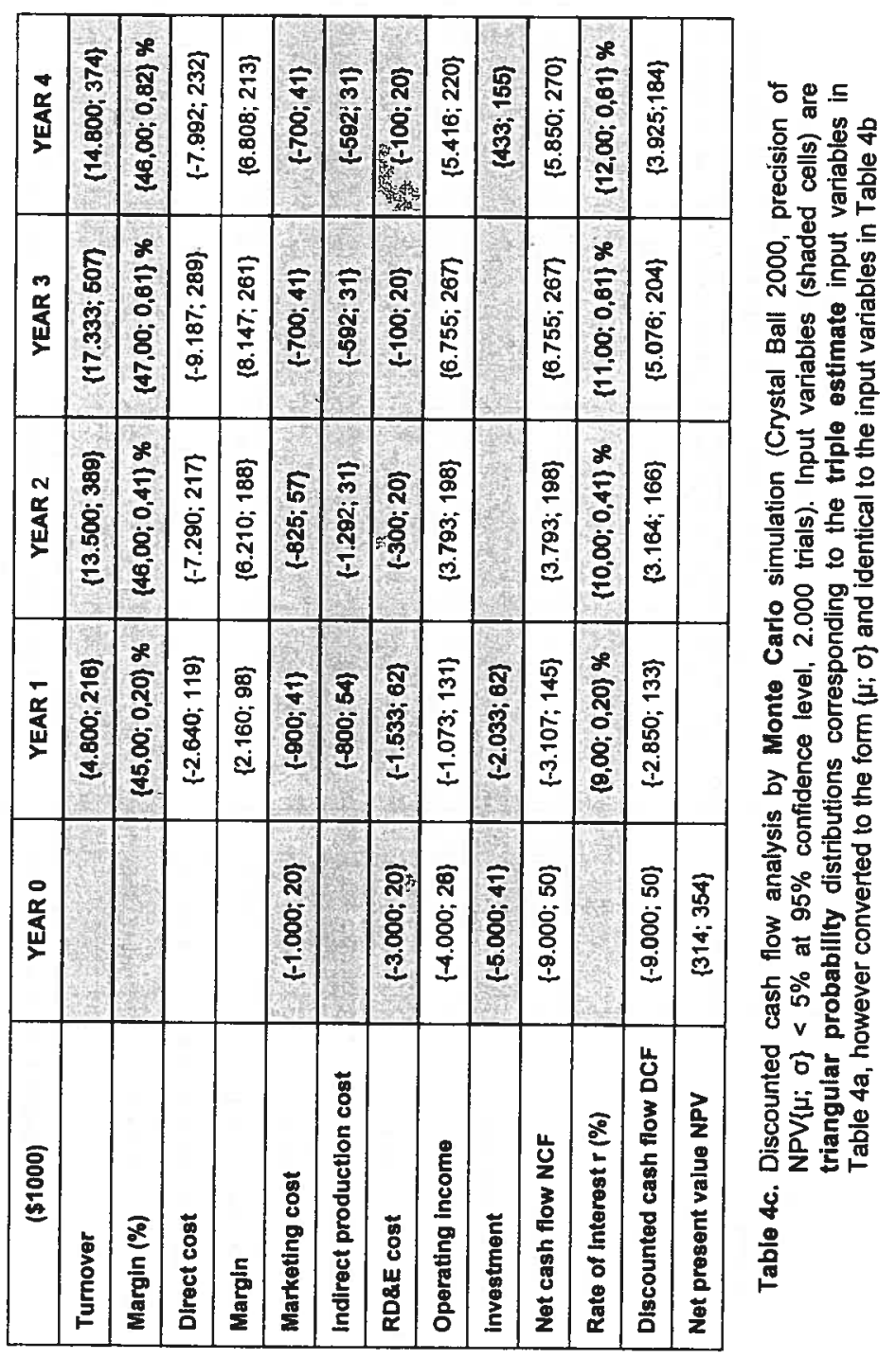




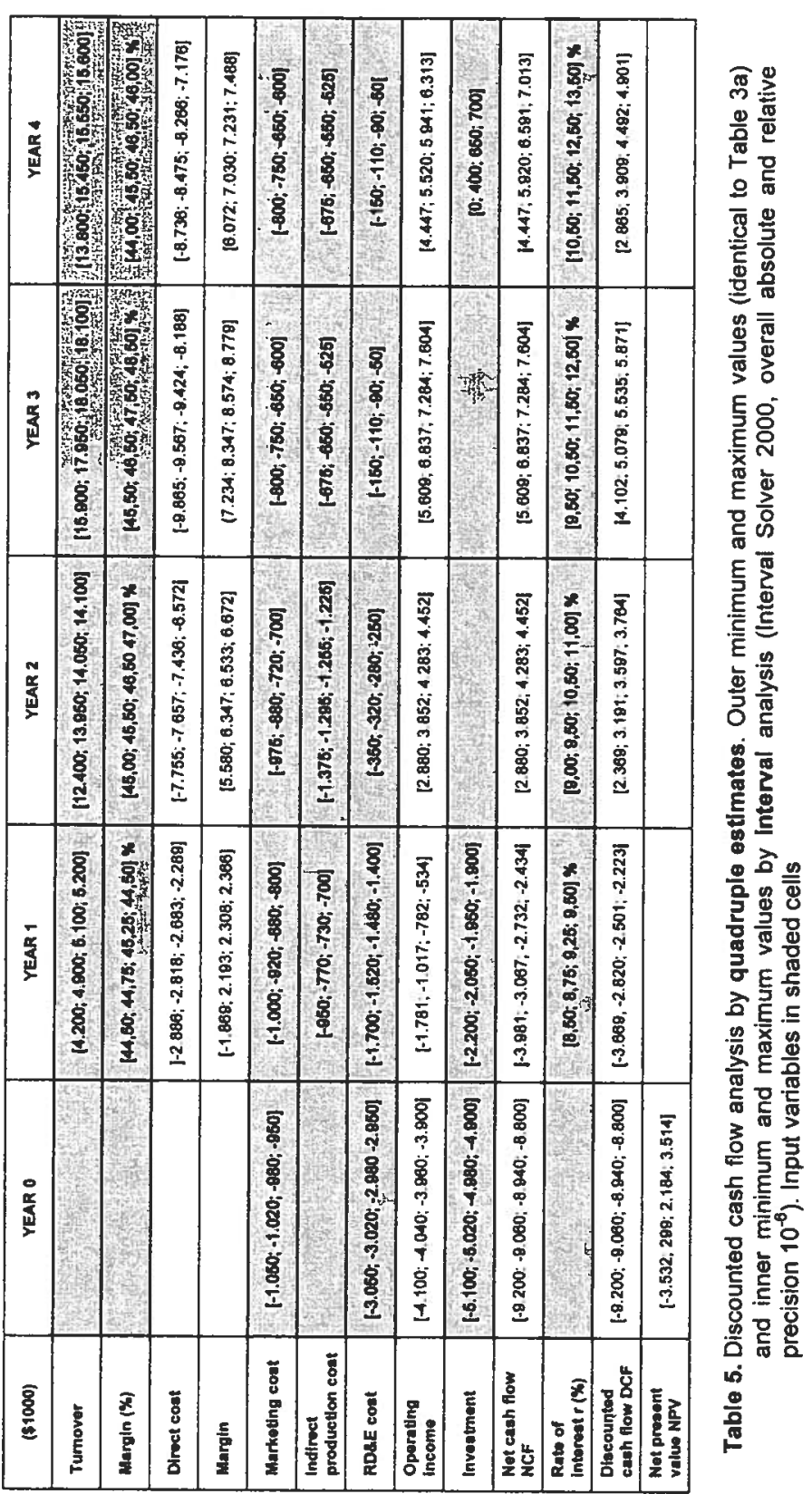

